\title{
Analysis of Atmospheric Circulation Patterns in the Babol Roud Watershed
}

Robab Razmi ( $\sim$ Robab.razmi1400@gmail.com )

University of Zanjan https://orcid.org/0000-0002-0667-8184

Narges Hesami

University of Zanjan

Zahra Rabiee

University of Zanjan

Mohsen Ghane

Islamic Azad University

\section{Research Article}

Keywords: Babol Roud, Heavy rainfall, Spectrum Analysis, Synoptic Patterns

Posted Date: November 1st, 2021

DOI: https://doi.org/10.21203/rs.3.rs-1034703/v1

License: (c) (1) This work is licensed under a Creative Commons Attribution 4.0 International License.

Read Full License 


\title{
Analysis of atmospheric circulation patterns in the Babol Roud watershed
}

Robab Razmi ${ }^{1 *}$, Narges Hesami ${ }^{2}$, Zahra Rabiee $^{3}$, Mohsen Ghane $^{4}$

*Corresponding Author: Robab Razmi, Phd Candidate at Zanjan university, Zanjan, Iran. Email: Robab.razmi@znu.ac.ir.

${ }^{2} \mathrm{PhD}$ student in Climatology, Department of Geography, Faculty of Humanities, University of Zanjan, Zanjan, Iran. Email: $\underline{n}$ hesami12@yahoo.com.

${ }^{3} \mathrm{PhD}$ student in Climatology, Department of Geography, Faculty of Humanities, University of Zanjan, Zanjan, Iran. Email: zahra_rabiee@ znu.ac.ir.

${ }^{4}$ Department of Civil Engineering, South Tehran Branch, Islamic Azad University, Tehran, Iran. Email: mohsenmohsengh@gmail.com.

\begin{abstract}
precipitation is a variable whose value, intensity, and type changes in temporal and spatial dimensions. the occurrence of heavy rainfall is an aspect of these changes which is a dangerous factor in the incidence of natural disasters such as flooding. In this study, with the aim of investigating the behavior of precipitation and discharge of Babol Roud watershed, the Talar station was selected as an indicator station. Then, the cycles governing precipitation and discharge parameters of the station were estimated at the annual scale (1976 - 2011) based on the spectral analysis technique. The results of spectral analysis on time series of discharge and precipitation at a 95\% certainty level indicate the existence of a common annual 2 cycle in discharge and annual precipitation. The coincidence of a 2 years old significant cycle in the time series of precipitation and discharge means that in 2 years the repetition of annual precipitation events affects annual discharge. The Extraction heavy rainfall in the Babol Roud watershed was examined the study of atmospheric conduct at the sea level pressure (SLP) and the elevation of the atmosphere medium level (500 hpa level) at the time of their occurrence. After grouping these days, based on cluster analysis technique, three patterns were determined as the dominant patterns of heavy rainfall in the Babol Roud Watershed.
\end{abstract}

Keywords: Babol Roud, Heavy rainfall, Spectrum Analysis, Synoptic Patterns.

\section{Introduction}

Participation due to surface currents, the effect on groundwater aquifers and the most important input data on hydrologic systems and effective process affecting water resources is of particular importance, its intensity, intensity, and its type changes in time and space dimensions. These changes cause rainfall to show different behaviors in these dimensions. one of these behaviors is the occurrence of heavy rainfall which is a risky factor in the emergence of natural disasters such as flooding. most of Iran's catchment areas, especially the northern regions of the country, produce destructive flooding every year. 
Therefore, identifying how to develop, amplify, and mechanism governing the synoptic patterns of torrential rainfall can provide the necessary base for predicting their occurrence. predicting the synoptic patterns before the occurrence of heavy rainfall, the effective factors on the occurrence of heavy rainfall can identify and evaluate its behaviors and take the necessary precautions to prevent possible damages and also the optimum use of these precipitation. The study of hydraulic statistics and flood events shows that the northern areas of Iran are among the most flood area in the country. Therefore, in this study, it was tried to study the synoptic conditions of synoptic systems with torrential rainfall in Babol Roud watershed to the two questions: what is annual precipitation following the return cycle? second, whether major synoptic factors had any effect on capturing heavy and torrential rainfall in the Babol Roud watershed or not?

Scientists and Climatologists have particular pay attention to the study of the behavior of these types of precipitation, mainly due to the importance of heavy precipitation and flooding, and they have mainly investigated the behavior of the various levels of pressure at the time of their occurrence.

For example, William et al. (2004) divided the heavy precipitation of the UK into three groups of Frontal Precipitation ,Convective Precipitation and Orographic Precipitation. The results indicated that a Frontal precipitation occurs when the relative humidity is more than $80 \%$ and a landing center moves from the $200 \mathrm{~km}$ range to the location towards to the heavy rainfall event.

Mohapatra and Mohani (2005) investigated the heavy rainfall features of $24 \mathrm{~h}$ above $125 \mathrm{~mm}$ in India, this rainfall caused by low - scale synoptic systems and low-pressure systems in the region. Lisat et al. (2007) investigated the dynamic and thermodynamic properties of the Cold air pools and cold springs of the European climate and their role in the heavy rainfall of Spain expressed. the results showed that the dynamic conditions of cold air pools were more important in the formation of heavy precipitation events.

Dong et al. (2008) began to analyze the synoptic analysis of a heavy precipitation 18 - day event in South Korea. They showed that in 1998, the presence of the barrier to the east of Manchuria, and the spread of pressure tropical high toward the west were the main causes of this heavy rainfall. Vide et al. (2008) investigated the precipitation of over $100 \mathrm{~mm}$ during the 1950 - $1950 \mathrm{~s}$. using the main component technique and the western Mediterranean fluctuation index, they identified seven effective patterns for this precipitation.

Schuenemann et al. (2009) investigated the synoptic patterns of the daily precipitation of Greenland. they have identified 35 different patterns of sea level and concluded that heavy rainfall is caused by Related cycles with offshore currents.

Inside Iran, the findings of Nasiri and Ghaemi (1999) regarding the analysis of synoptic and dynamic patterns of heavy rainfall in the Karkheh and Dez watersheds that lead to major floods indicate the existence of two separate Mediterranean systems and Sudan, each of which is affected by the rainfall in this basin, respectively. Lashkari (2000) in the study of the mechanism of formation of the Red Sea convergence zone states that the deepening of the North African ship and its expansion on Sudan activates the Red Sea convergence zone and as a result of heavy rains in southwestern Iran.

Asadi and Masoudian (2001) in the study of Shiraz flood synoptics, analyzed atmospheric systems causing heavy rainfall during January 17-22, 2001 and concluded that Mediterranean rainfall systems Sudan - The Red Sea is one of the causes of this flood.Moradi (2006) by examining the floods on the southern coast of the Caspian Sea, concluded that three types of air masses and compression systems, including the Caspian Sea migratory cycles and cyclones, have been effective in precipitation on the southern coasts.

Mohammadi (2008) studied the thickness of the atmosphere at the time of heavy rainfall in Iran and concluded that the fall of cold air from high latitudes and its collision with warm air transferred from lower latitudes, especially northwest Africa and Saudi Arabia. , Has created a region of severe pressure on Iran, which 
has played an important role in the occurrence of such rains. Khoshhal and Khosravi (2009) in a study investigated the origin and path of moisture of super-heavy rainfall in Bushehr province and concluded that the sources of moisture supply of such rainfall are tropical regions of East Africa, Indian Ocean, Arabian Sea and Gulf of Aden., The Red Sea, Oman and the Persian Gulf.

Rahimi et al. (2010) studied the heavy rainfall in the arid regions of Iran using the Gamble statistical index and identified the synonymous patterns of these rainfalls. Analysis of these patterns showed that the most important factor in the formation of heavy rainfall is the eastward movement and the strengthening of the eastern Mediterranean landing in the middle troposphere, which occurs simultaneously with the downward movement of the polar vortex system. Masoudian and Mohammadi (2010) studied heavy rainfall in Iran and found that the European high-pressure and low-pressure model of Iraq was effective in the event of these rains. Gandamkar and Aminpour (2011) by examining the synoptic conditions of flood precipitations in Shahreza, concluded that the formation of low-pressure centers on the ground below the divergence zone of $500 \mathrm{hPa}$ causes instability and consequently rainfall in Shahreza. Be.

Mofidi et al. (2011) studied the synoptic patterns of heavy winter rainfall on the southern shores of the Caspian Sea. Findings showed that heavy winter rainfall on the southern shores of the Caspian Sea is the result of the establishment of three high-pressure, combined and low-pressure patterns on the Caspian region. Askareh et al. (2012) studied the synoptic effects of heavy rainfall in Gilan province during the statistical period of 19762005 using the method of percentiles and the Lund correlation method. The results indicate the effect of highpressure systems on heavy rainfall in five models.

Lashkari et al. (2012) analyzed the synoptic heavy rains in Isfahan province during a statistical period of 20 years and concluded that the low-pressure integration patterns of the Mediterranean and Sudan cause heavy rains in Isfahan province. Babolrood watershed is located in the south of Babol city, located in Mazandaran province, with an area of 51725 hectares, between 52 degrees and 38 minutes to 52 degrees and 55 minutes east longitude and 36 degrees and 2 minutes to 36 degrees and 22 minutes north latitude.

This area has 5 main sub-areas called Babelk, Esklim, Karsang, Azarrud and lowlands. The minimum height of the basin is 55 meters and the maximum is 3317 meters. The average annual rainfall is $821.8 \mathrm{~mm}$. The location of the study area in Iran is shown in Figure (1).

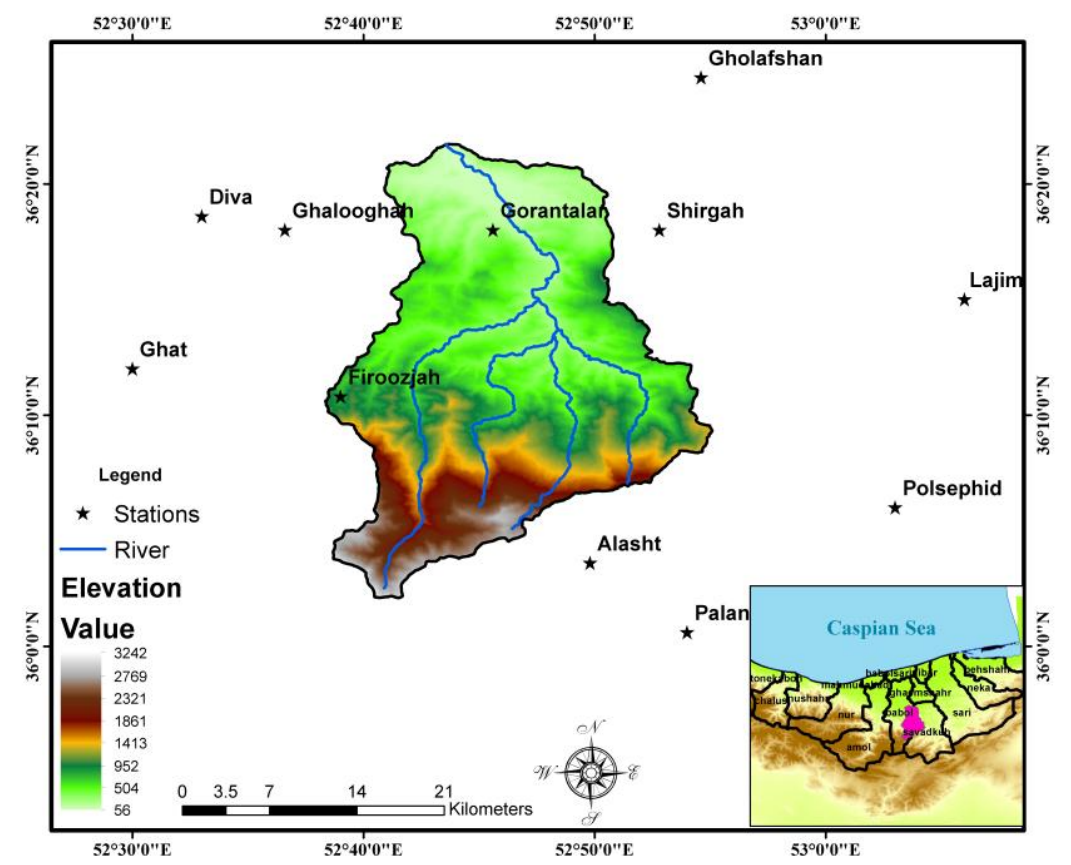

Fig.1. Geographical location of Babol Roud watershed in northern Iran 


\section{Data}

In order to study the temporal-spatial changes of heavy precipitations, more than the environment method to circular is mostly used. Because in this way, the researcher focuses on the specific precipitation that he wants. Therefore, for this research, two types of environmental data and circulation data were used.

\section{Environmental data}

For the present study, data related to daily precipitation of 11 rain gauge stations and stations outside the basin and daily discharge of Quran Hall hydrometric station were selected for the statistical period of 21/03/1991 to $31 / 06 / 2012$. Due to the lack of observable stations in the region, an investigation network was expanded outside the area. After the formation of the database, 95th percentile values for each month of the year were extracted for all stations. Then, the number of days that lead to heavy rainfall was selected, and synoptic patterns have resulted in these rains were identified. In order to study the discharge cycles and annual rainfall, Quran Talar station was designated as a landmark station in the region. The station is located in coordinates, $50^{\circ} 45^{\prime} \mathrm{km}$ east longitude and $65^{\prime} 31^{\circ}$ north latitude, and an elevation of 949 meters above sea level (Fig. 1)

\section{Atmospheric data}

Data on atmospheric variables used in this study include sea level pressure (SLP) data, and $500 \mathrm{hPa}$ surface altitude data with a spatial resolution of $2.5 \times 2.5$ degrees arc. These atmospheric data were obtained from the NCEP / NCAR Database of the US National Oceanic and Atmospheric Government. In this database, the data of the period of 1948 have been located so far and four observations are made for each day at synoptic hours $(00$, 06, 12 and 18). In this research, the data of 00 hours have been used (Rahimi et al., 2003, 52).

To investigate study the above atmospheric data, the study area was selected to be wider than the territory of Iran. This range includes areas between longitude 10 degrees west to 120 degrees east and latitude zero to 80 degrees north. in this way, the study area is covered with 1749 cells. the purpose of this study is to identify synoptic phenomena and more awareness of the formation of these systems, their movement path and how they spread and their impact on Iran and the study basin

\section{Methods}

\subsection{Investigation of precipitation and discharge cycles}

First, it is tried to investigate the oscillation conduct of precipitation and discharge at the Quran Talar station, , which has the maximum length of the statistical period in Babol Rood watershed. The recognition the conduct of precipitation and discharge, especially its oscillation conduct, is one of the essential foundations in environmental management and planning based on climatic knowledge and can play a significant role in improving the level of water resources management.

Spectral analysis is a suitable tool for extracting cycles in time series. The main advantage of spectral analysis in other statistical methods is the transition from space and time to inverse space (frequency)which will cause a significant decrease in the volume of statistical computation.

spectral analysis method is the Fourier transform (Taghvi et al. , 2011). The time series $Z_{t}$ ), length n, $\left(\left\{Z_{t}\right\}_{t=\uparrow}^{n}\right)$ is written as a Fourier transform (Asakerh, 2009).

$$
Z_{t}=a_{v}+\sum_{t=0}^{q}\left(a_{i} \cos 2 \pi f_{i} t+b_{i} \sin 2 \pi f_{i} t\right)
$$

Which $Z_{t}$ is the climatic element studied at time t and $f_{i}$ the frequency of repetition of observations (reverse of the return period) and is denoted by $f_{i}=\frac{i}{n}-q i=1, r, \ldots, q$ ( $\left(a_{i} \cos 2 \pi f_{i} t+b_{i} \sin 2 \pi f_{i} t\right)$, around a fixed mean $\left({ }^{a} \cdot\right)$, determine the series behavior. The number of 
these harmonics is a maximum of half the length of the data. The Fourier model can also be considered as a linear regression model and Fourier coefficients including $\left(b_{i}, a_{i} a_{*}\right)$, like a multivariate regression, are obtained using the least squares error method. The variance of the frequency $f_{i}$ and length of the individual statistical period is as follows:

$$
\left.I\left(f_{i}\right)=\frac{n}{\Uparrow}\left(a_{i}^{\Uparrow}\right)+b_{i}^{\Uparrow}\right) \quad i=1, \uparrow, \ldots, q
$$

The graph that shows the values $I\left(f_{i}\right)$ in front of $\mathrm{i}$ is called the periodogram.

The periodogram is a ratio of the distribution of variance at the fundamental frequencies and the estimation of the ups and downs of the spectrum.

\subsection{Extract patterns}

First, we tried to identify the following days with heavy rainfall. For this purpose, the thresholds provided in the CLIVAR climate predictability and variability project were used. for this purpose, we use the thresholds presented in the project reliability and CLIVAR climate variability project. The percentile index is one of the most common methods for calculating and determining heavy rainfall (Mofidi et al., 2007: 134). Based on these indicators, the total rainfall of days with rainfall equal to or higher than the 95th percentile (R95p) of the base period, is considered as days with heavy rainfall (Rahimzadeh, 2005, 3).In order to analyze the synopticscanning of heavy rainfall in Babolrood watershed, based on the mentioned index, 435 days of 7305 days were selected as Continuous days with heavy rainfall.

For this purpose, first, the database was prepared on a daily basis using data taken from the Ministry of Energy, and the daily data of 11 stations were adjusted separately from month to month. Then, for each month, 95th percentile index and 435 days were selected, in GARDS software environment, sea level maps (SLP) and altitude level of $500 \mathrm{hPa}$ were extracted .After obtaining the numbers of each cell of all maps, cluster analysis technique by Archiving method and input integration method (WARD) were applied to sea level pressure maps. Finally, based on trial-and-error method, the best cluster was selected which showed the lowest intragroup variance and the highest intergroup variance. Based on the results dendrogram, three groups were selected as groups with the highest similarity.

\section{6.research findings}

\section{a)To identify annual precipitation cycles}

Figure (2) was determined periodogram, the spectrum and confidence interval for the annual rainfall time series of Talar Quran station. The cycles are prepared in two scales. The bottom horizontal axis is the harmonic (cycle in 36 years). The vertical axis also shows the estimated spectrum (variance). The broken line represents the spectrum (amount of variance) for different frequencies (times).

The dashed line above the chronograph is a significant limit at the $95 \%$ confidence level and the continuous dashed line is the continuous zero limit (the randomness limit of the spectrum). If the value of the spectrum is higher than this line, it indicates an oscillation in the corresponding frequency.

As shown in the periodical, the two-year cycle has the highest diffraction compared to other harmonics and is statistically significant at $95 \%$ confidence level. The first harmonization indicates the existence of a nonsinusoidal cycle (trend) in the annual rainfall time series. Simultaneous occurrence of a significant 2-year cycle in the rainfall and discharge time series means that in every 2 years, the repetition of annual rainfall events also affects the annual discharge. 


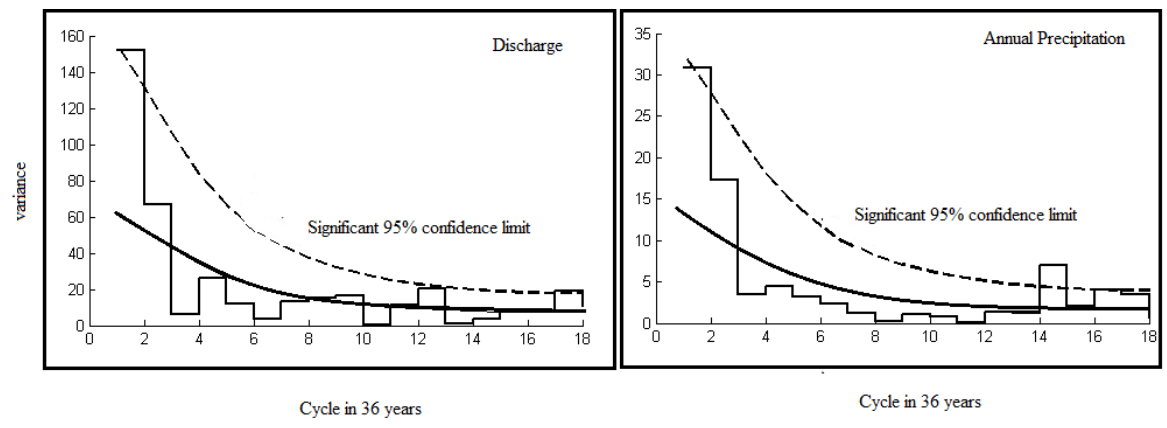

Fig.2. periodogram of Discharge time series and annual rainfall at $95 \%$ confidence level in Babolrood basin

\section{B) Identification of synoptic patterns of heavy rainfall in Babolrood watershed}

As previously stated, to determine the patterns leading to heavy rainfall in the Babolrood watershed, by performing cluster analysis, three precipitation patterns were determined. The number of days of each group and the date of the representative of the torrential rains are presented in Table 1.

Table 1: Number of days each group and date of representative days

\begin{tabular}{|c|c|c|}
\hline Date & days & groups \\
\hline $01 / 01 / 1992$ & 62 & First group \\
\hline $10 / 10 / 1995$ & 206 & Second group \\
\hline $01 / 11 / 2001$ & 167 & Third group \\
\hline
\end{tabular}

\section{Synoptic analysis of the first group pattern (Iceland low pressure / polar - Siberian high pressure)}

Figure (3) shows the average sea level pressure for 62 days of the first group along with the coefficient of pressure changes of these days. In this pattern, the formation of a steep belt along the $55-60^{\circ}$ north orbits is the main point of separation of the low pressure northern and high-pressure zones of the middle latitudes, as well as the boundary between cold northern and warm southern air. The pattern of these lines shows that the surface pressure in Iran has been a high-pressure pattern. The altitude pattern at the level of 500 geopotential meters represents the orbital pattern of this elevation level.

In Western Europe, excessive heat penetration of low-altitude latitudes has dramatically increased the compaction of elevation lines. As with surface pressure, the maximum compaction is seen along circuits 60-45 degrees north. The change in altitude of 500 from west to east has caused the formation of several short waves in the bed of long waves of this altitude. Since short waves are a factor in intensifying instabilities, so the highest intensity of altitude changes can be seen in the areas dominated by these waves. Iran is mainly in the path of the impact of these short waves and the conditions have been created for the intensification of instabilities in Iran. The group's representative day is January 4, 1992. 


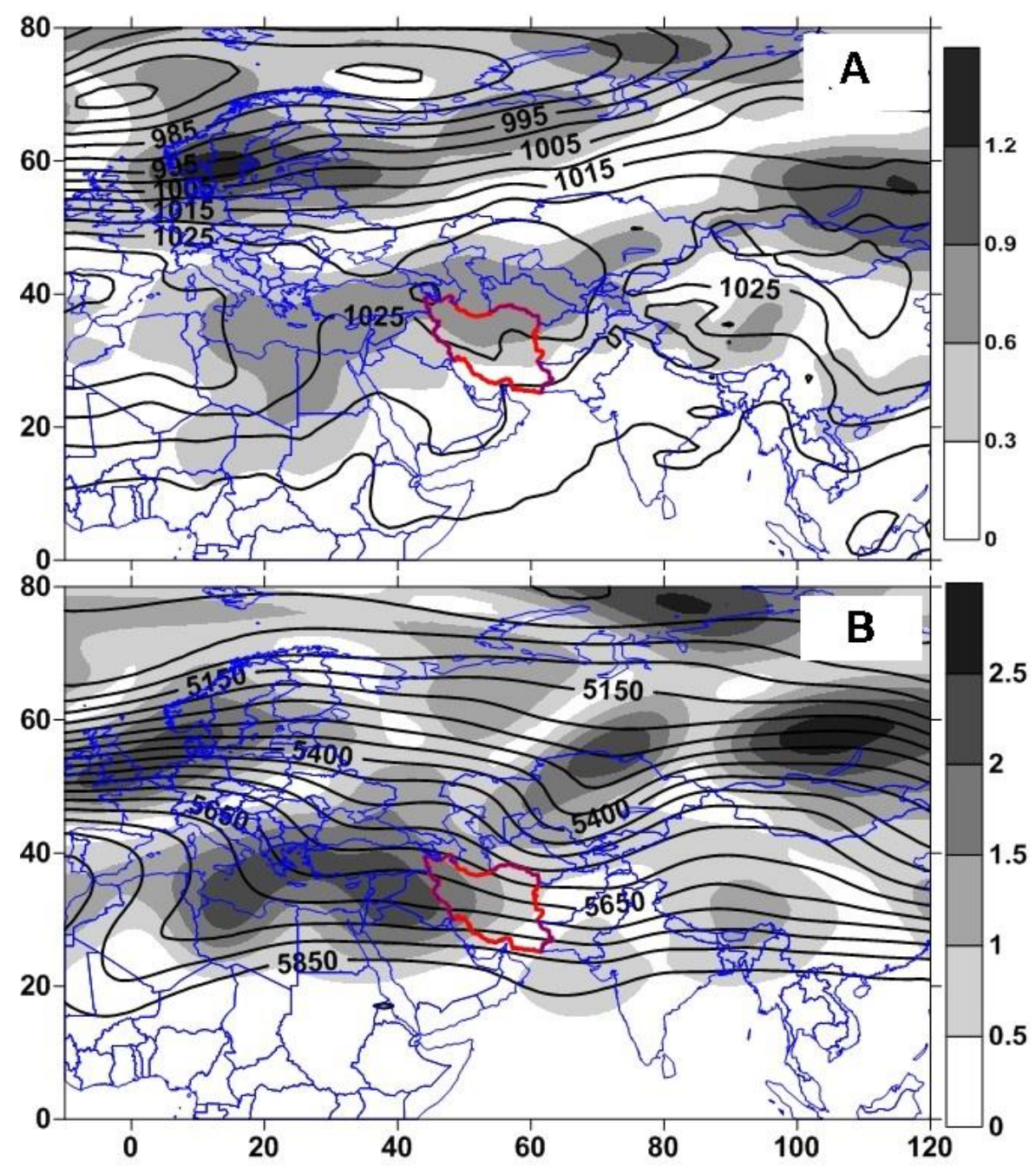

Fig.3.the mean and coefficient of sea level pressure changes (A)and the level of the level of 500 hpa (B)related to the first group

Synoptic analysis of the second model (Siberian hypertension - low polar pressure)

The average pressure of 206 days in the second group after averaging the pressure values of this number of days is shown in Figure (4).

This pattern represents the formation of the predominant pattern of cold and low pressure in northern Europe and Siberia with an average central pressure of $998 \mathrm{hPa}$ and hot and high surface pressure in East Asia with a central pressure of $1036 \mathrm{hPa}$. The interaction between these two pressure levels has created a very steep area in the $50^{\circ} \mathrm{N}$ degrees. If we consider the 1016 hectopascal co-pressure line as the boundary separating highpressure and low-pressure centers, the areas located between 20-50 degrees north orbits are considered as highpressure areas. Iran is also affected by these compression systems due to its location in the middle latitudes. So that compression lines of 1024-1020 hPa are the dominant pressure levels in Iran.

The average surface height of $500 \mathrm{hPa}$ second group mainly follows the orbital pattern. The vast territory of the high-altitude area to the north reduces the range of low-lying areas, resulting in a strong elevation pattern in the range of 40-55 degrees north latitude in Central Asia. Variations in altitude in the range of circuits have increased and decreased the height of these surfaces and have created short and long waves in the orbital bed of these altitude levels. 


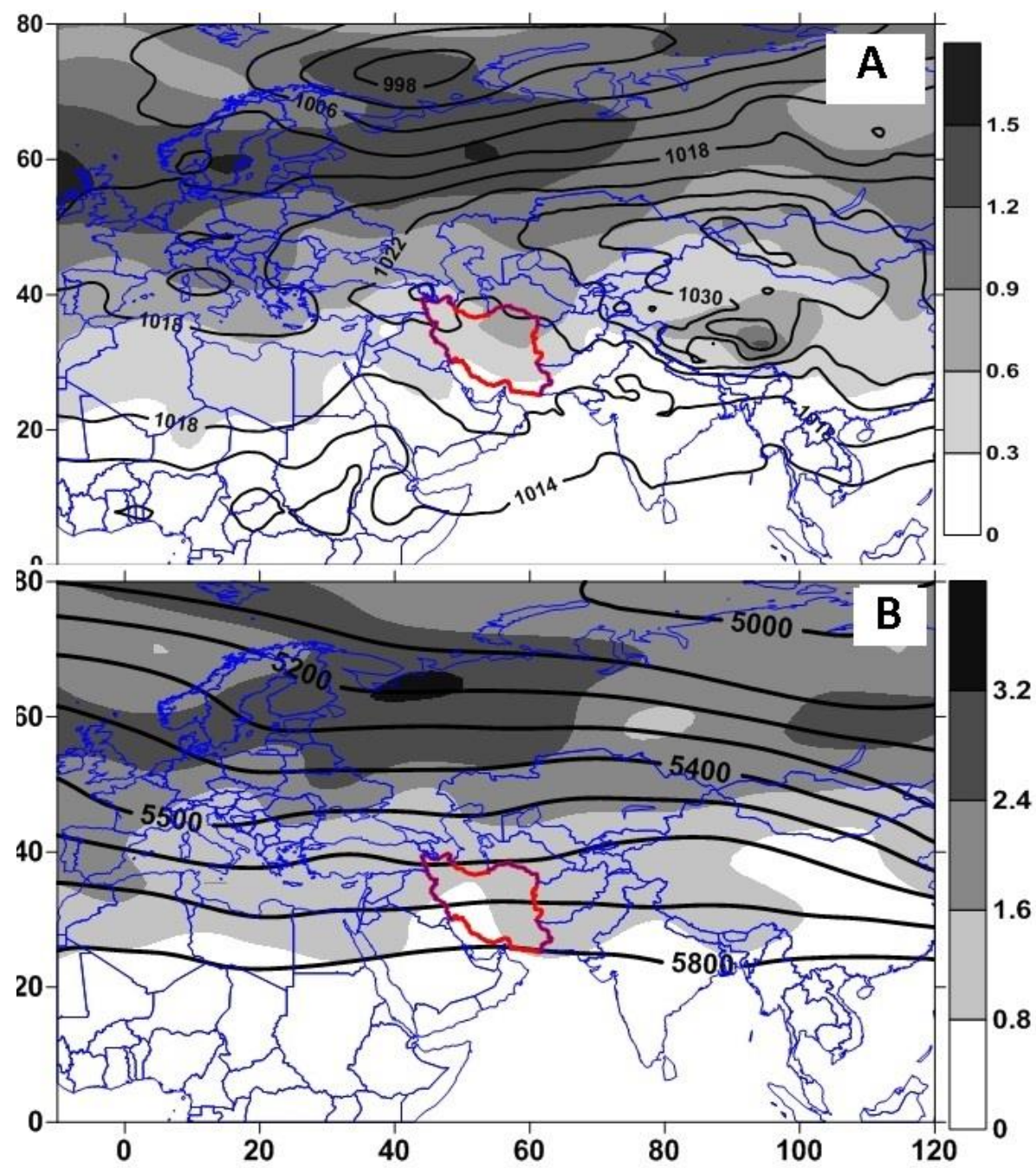

Fig.4.The mean and coefficient of sea level pressure variations (A) and surface height of $500 \mathrm{hPa}(\mathrm{B})$ belongs to the second group

\section{Synoptic analysis of the third model (Iceland low pressure-Siberian high pressure)}

$38 \%$ of the days are in this pattern. The average sea level pressure map shows the formation of a high-pressure region in Siberia with a pressure of more than $1040 \mathrm{hPa}$ in the center. The predominant pressure conduct in the northern parts of Europe in Iceland also indicates the formation of a low-pressure center. 

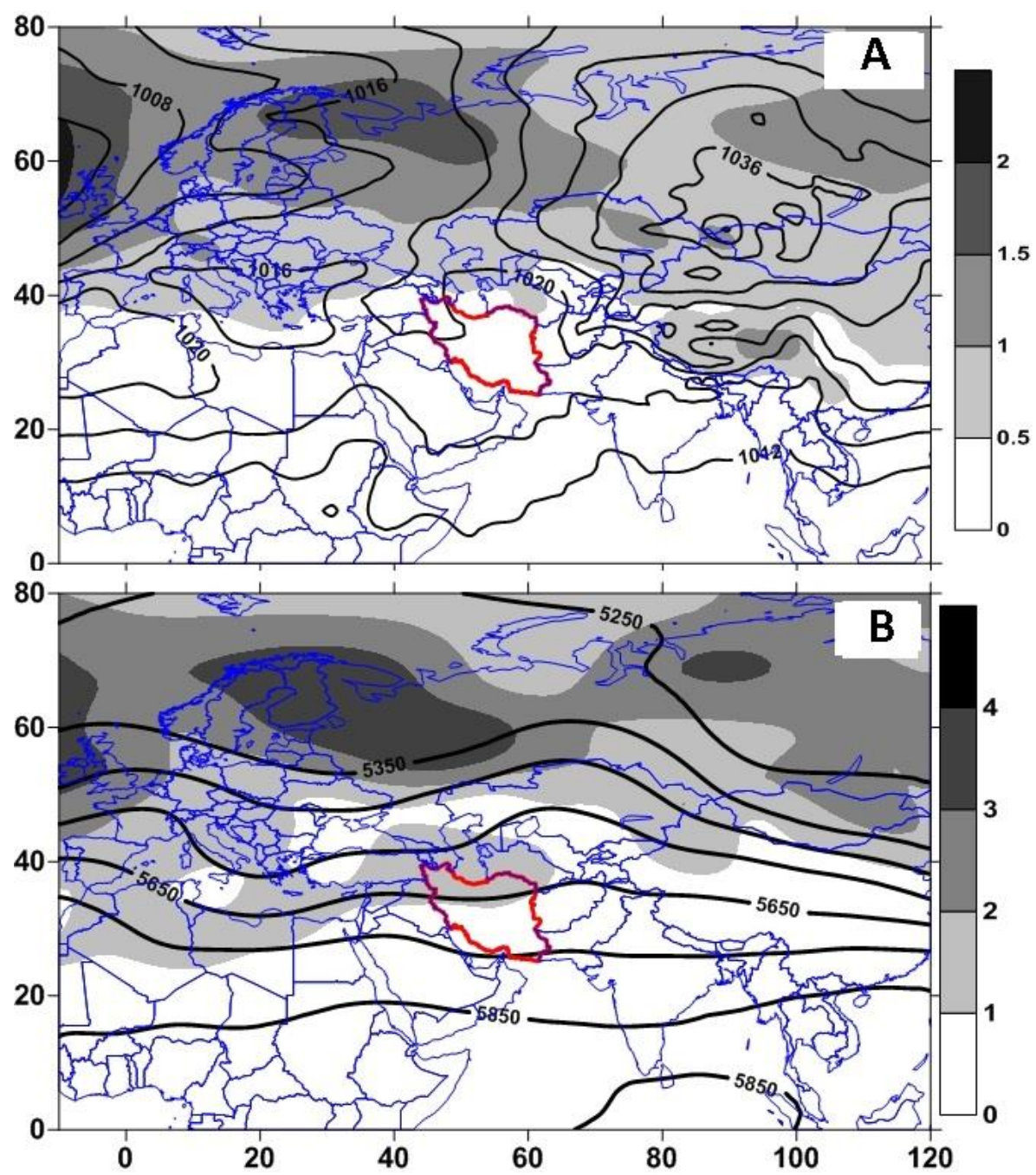

Fig.5. The mean and coefficient of sea level pressure changes (A)and the level of the level of $500 \mathrm{hpa}$ (b)related to the second group

In the meantime, the rotation of the high-pressure center located in Siberia and the penetration of its tabs towards Iran, has had the most important impact on the characteristics of pressure in the country. Global warming in Iran has caused low pressure lines to penetrate the northern latitudes. Therefore, the pressure conflict in the parts located in Turkmenistan and Afghanistan has increased sharply.

The general pattern governing the mean altitude of the atmosphere in the days of the third group shows the relative order of the 500 geopotential cohesive lines. In higher circuits, due to atmospheric cooling and unevenness in cooling and heating of the atmosphere, due to the infiltration of heat from low latitudes to high latitudes and with cold air penetration of high latitudes to lower circuits, the order of overlapping lines is lost and short waves at medium altitudes the atmosphere is created. Therefore, changes in altitude have also had significant parts.

\section{Conclusion}

In the present study, an attempt was made to investigate the conduct Discharge and annual rainfall and consequently heavy rainfall in the Babolroud watershed using statistical-synoptic techniques. The results indicate the existence of significant sinusoidal and non-sinusoidal cycles on an annual scale, so that the 2-year sinusoidal cycle in the rainfall and discharge time series is at the level of $95 \%$ confidence in the predominant behavior of these elements.

Since the northern part of Iran is one of the most important parts of the country, the most important purpose of this study was to investigate and identify the synoptic conditions of systems with flood-precipitation systems in the Babolroud watershed. After determining the three patterns as the dominant patterns of heavy rainfall in 
Babolrood watershed, it was found that the formation of short waves in the bed of long waves and its direction to Iran and the impact of upper atmospheric factors is the most important cause of heavy rainfall in the Caspian coast and Babol Roud watershed. It is found that the formation of short waves in the bed of high waves and its conductivity towards Iran and the effects of the upper atmospheric factors are the main causes of heavy rainfall on the Caspian Sea and Babol Roud Watershed.

\section{Declarations}

Ethical approval: Not applicable.

Consent to participate: Written and signed consent was obtained by all research participants.

Consent to publish: Not applicable.

Conflict of interest: The authors declare competing interests

Funding Statement: Not applicable.

Author's Contribution: Both authors jointly conceived and wrote the piece.

Availability of data and material: Not applicable.

Code availability: Not applicable.

Acknowledgements: The comments of the reviewers are appreciated for helping to improve the clarity of the article.

\section{References}

Asadi.A., Masodian.S.A, (2004). the synoptic examination of the 2010 flood waters in Shiraz, the second national conference of water and soil resources.

Dong - Kyou L , jeong - Gyun p, and Joo - Wan K. (2008), Heavy Rainfall Events Lasting Days from July 31 to August 17, 1998, Over Korea, Journal of the Meteorological Society of Japan, 86 (2) :313-333.DOI: https://doi.org/10.2151/jmsj.86.313.

Kamal.O. (2011). synoptic meteorological. university of Yazd.2th Publications.

Taghavi.F., Naseri.M., Bayat.B., Motevalian,S.S., Azadifard,D.(2011). Determination of patterns of climate behavior in different regions of Iran based on spectral analysis and cluster analysis of precipitation and temperature, natural geography, $77: 109-124$.

Khoshhal.J.,Khosravi.M., (2009). Identifying the source and route of moisture in Bushehr super heavy rainfall, Journal of Geography and Development, 16: 7-28. DOI: 0.22111/GDIJ.2009.1173.

Rahimi.D., Khoshhal.J., Alizade.T,(2010). Statistical analysis - Synonymy of heavy rainfall in arid regions of Iran (Case study: Kerman province), Geography and Regional Development, 14 :51-69.

Rahimzade.F.,(2005). "Study of changes in precipitation limit values in Iran" Nivar, 58(57): 1-7.

Asakerh.H., (2009). Spectral analysis of time series of annual temperature of Tabriz, Geographical Research Quarterly, 94: 33-50.

Asakerh.H., (2012). An Analysis of September Heavy Rainfall in Relation to Synoptic Patterns in Gilan Province (1976-2005), Natural Geography Research, 2: 51-66.

Asakerh.H., Khoshraftar.R., Sotodeh., F.(2012). An Analysis of September Heavy Rainfall in Relation to Synoptic Patterns in Gilan Province (1976-2005), Natural Geography Research, 2: 51-66.

Gandomkar.A., Aminpour., M.(2011). Synoptic analysis of torrential rains in Shahreza, Proceedings of the National Conference on Desert Ecology, Tourism and Environmental Arts, Islamic Azad University of Najafabad. 
Liasat M.C, Mart, F. and Barrera,A, (2007), From the Concept of Kaltlufttropfen (cold air pool) to the cut - off Low , The Case of September 1971 in Spain as an Example of their Role in Heavy Rainfalls, Meteorol Atmos Phys, 96: 43- 60 .

Lashkari., H. (2000). Mechanism of Evolution of the Red Sea Convergence Zone, Geographical Research Quarterly, 58: $167-184$.

Lashkari., H., Ghaemi. H., Hojati.Z., Amini.M, (2012). Synoptic analysis of heavy rainfall in Isfahan province, Natural Geography Research, 4: 99-116. DOI: 10.22059/JPHGR.2012.30244.

Lupikasza.E.(2010). Relationships between occurrence of high precipitation and atmospheric circulation in Poland using different classifications of circulation types. Physics and Chemistry of the Earth, Parts A/B/C. DOI: https://doi.org/10.1016/j.pce.2009.11.012

Moradi.H.(2006). Prediction of floods based on synoptic locations on the southern shore of the Caspian Sea, Geographical Research, 55: 109-131.

Mohammdi.B.(2008). Identification of Barley Thickness Patterns (Case Study: Heavy Rainfall in Iran), Geographical Thought, 3: 131-149.

Masodian.S.A., Mohammdi.B.,(2010). Synonymous analysis of heavy rainfall in Iran (Case study: November 1994), Geography and Development, 19: 47-70.

Mofidi.A, Zarin.A.,Ghobadi.Gh.,(2007). Analysis of the synoptic pattern of heavy and partial autumn rainfall on the southern shores of the Caspian Sea "Earth and Space Physics, 33(3): 154-131.

Mofidi.A, Zarin.A.,Ghobadi.Gh.,(2011). Identification of synonymous patterns of heavy winter rainfall on the southern shores of the Caspian Sea, Journal of Geography and Environmental Planning, 42: 23-40.

Mohapatra. M Mohanty. UC, (2005). some characteristics of very heavy rainfall over Orissa during summer monsoon season, J. Earth Syst Sci, 114 (1): 17- 36. DOI: https://doi.org/10.1007/BF02702006.

Nasiri.B., Ghaemi.H., (1999). Analysis of Synoptic and Dynamic Patterns of Karkheh and Dez Precipitation, Geographical Research Quarterly, 85: 177-185.

Schuenemann, keah. C, Cassano Johan j, Joel Finnis, (2009). synoptic Forcing of precipitation aver Greenland: climatology for $1961 \quad-\quad 1999$, Journal of Hydrometeorology, 60- $78 . \quad$ DOI: https://doi.org/10.1175/2008JHM1014.1.

Tencer, B., Weaver, A., Zwiers, F., (2014). Joint occurrence of daily temperature and precipitation extreme events over Canada. J. of Applied Meteorology and Climatology 53:2148- 2162. DOI: https://doi.org/10.1175/JAMCD-13-0361.1.

Tencer, B., Bettolli, M.L., Rusticucci, M., (2016). Compound temperature and precipitation extreme events in Southern South America: associated atmospheric circulation and simulations by a multi-RCM ensemble. Clim. Res. 68:183-199. DOI:http://dx.doi.org/10.3354/cr01396.

Vide M. J, Lorenzo .A Bustins Lopez.J.A, M. J.Cordobilla, Manuel, Garcia . A, J ,M. raso. (2008). Torrential rainfall in Science and Research, 99- 105.

Ward, J.H., (1963). Hierarchical grouping to optimize an objective function. J. Am. Stat. Assoc. 58:, $236-244$. https://doi.org/10.1080/01621459.1963.10500845.

Wilks, D.F., (2011). Statistical Methods in the Atmospheric Sciences, third ed. Ac. Press, p. 627pp. 
Xie, P., Chen, M., Shi, W., (2010). CPC global gauge-based analysis of daily precipitation, Preprints. In: 24th Conf. On Hydrology, vol. 2. Amer. Meteor.

William H. Hand, Neil I Fox, Christopher G Collier, (2004), A study of twentieth - century extreme rainfall events in the United Kingdom with implications for recasting, Meterol. Appl. 11:15-31. DOI: $10.1017 / \mathrm{S} 1350482703001117$

Soc, Atlanta, GA. Zscheischler, J., Westra, S., Van Den Hurk, B.J.J.M., Seneviratne, S.I., Ward, P.J., et al., (2018). Future climate risk from compound events. Nat. Clim. Change 8 (6):469-477. DOI: https://doi.org/10.1038/s41558-018-0156-3.

YeYang.Y, Gao.M. NaruXie.N, Gao.Z.,(2020). Relating anomalous large-scale atmospheric circulation patterns to temperature and precipitation anomalies in the East Asian monsoon region.Atmospheric Research. 232:104679.https://doi.org/10.1016/j.atmosres.2019.104679:105489.https://doi.org/10.1016/j.atmosres.2021.105 $\underline{489}$.

Huang Y, Cui X, Li X. (2016). A three-dimensional WRF-based precipitation equation and its application in the analysis of roles of surface evaporation in a torrential rainfall event. Atmospheric Research. doi.org/10.1016/J.ATMOSRES.2015.09.026

Toshifumi Mukunoki T, Daisuke Suetsugu D, Atsushi Koyama A. (2021). Reconnaissance report on geotechnical damage caused by a localized torrential downpour with emergency warning level in Kyushu, Japan. Soils and Foundations. https://doi.org/10.1016/j.sandf.2021.01.008.

Schlögl M, Fuchs S, Heiser M. (2021). Trends in torrential flooding in the Austrian Alps: A combination of climate change, exposure dynamics, and mitigation measures. Climate Risk Management. DOI: https://doi.org/10.1016/j.crm.2021.100294.

Sridhara Nayak S, Tetsuya Takemi T. (2020). Atmospheric driving mechanisms of extreme precipitation events in July of 2017 and 2018 in western Japan.Dynamics of Atmospheres and Oceans. DOI: https://doi.org/10.1016/j.dynatmoce.2020.101186.

Om K.C., Ren G, Kang-Chol O. (2018).Climatological characteristics and long-term variation of rainy season and torrential rain over DPR Korea.Weather and Climate Extremes. DOI: https://doi.org/10.1016/j.wace.2018.09.003.

Bartoszek K, Matuszko D. (2020). The influence of atmospheric circulation over Central Europe on the long-term variability of sunshine duration and air temperature in Poland. Atmospheric Research. DOI: 10.1016/j.atmosres.2020.105427

Hamal K., Sharma S., Khadka N. (2021). Changing pattern of drought in Nepal and associated atmospheric circulation. https://doi.org/10.1016/j.atmosres.2021.105798. 